RESEARCH PAPER RP682

Part of Bureau of Standards Journal of Research, vol. 12, May 1934

\title{
EFFECT OF EXPERIMENTAL CONDITIONS ON THE MEAS- UREMENT OF AIR PERMEABILITY OF PAPER
}

\author{
By F. T. Carson
}

\section{ABSTRACT}

By means of the sensitive instrument recently developed at the Bureau of Standards, a careful study has been made of the relation of the rate of flow of air through paper to the experimental conditions. The results show that with few exceptions the flow of air is proportional to the pressure difference, for small pressure differences; proportional to the time of flow; proportional to the effective area of the specimen; and inversely proportional to the thickness of the material. With the type of measuring instrument used the results do not depend upon the viscosity of the air. The effect of relative humidity is unpredictable. The air permeability of paper was found to increase somewhat with decreasing absolute pressure, an unexpected behavior which may be associated with an elastic expansion of the structure.

Except for the absolute-pressure results, all the data agree remarkably well with Meyer's equation for the flow of a gas through a long capillary tube, and indicate that the air passages in paper behave as if they were a group of capillary tubes having an average length of many times the thickness of the sheet.

A comprehensive definition of air permeability in relation to paper and fiber board is presented, and suggestions are made relative to a standard testing method.

\section{CONTENTS}

I. Introduction _.

II. Relation of the rate of flow of air through paper to various experimental conditions ...

1. Theoretical relations .

2. Effect of pressure difference on rate of flow of air

3. Effect of time on rate of flow of air

4. Effect of area on rate of flow of air

5. Effect of temperature on air permeability

6. Effect of relative humidity on air permeability _._._. _._._. 597

7. Thickness of the sheet and air permeability

8. Effect of absolute pressure on air permeability

III. Nature of the air passages in paper

IV. Suggestions for a standard method of measuring the air permeability of paper

1. Nomenclature, definition, and unit of expression

2. Apparatus and testing conditions

\section{INTRODUCTION}

The development of the sensitive air permeability testing instrument illustrated schematically in figure 1 has been described in a previous paper. ${ }^{1}$ The new instrument was designed to obtain accurate values for a wide range of materials. An annular cell DD surrounds the permeability cell $\mathrm{C}$ and serves to by-pass air that leaks in at the edges of the specimen $\mathrm{S}$. Conditioned air at atmospheric pressure has 
access to the specimen above both cells. A capillary-tube flow meter, consisting of a number of capillaries A, B, etc., of different capacities and a kerosene manometer $M$, is connected in series with the cell $\mathrm{C}$. One capillary at a time can be opened to the air stream. The capillaries are calibrated against a standardized meter. A partial vacuum in the instrument is produced by an air pump $\mathrm{P}$, resulting in a pressure drop across the instrument not exceeding about $40 \mathrm{~g} / \mathrm{cm}^{2}$. Specially designed pressure regulators $R_{1}$ and $R_{2}$ maintain unvarying pressure heads $h$ and $H$ across the specimen and the flow meter during the

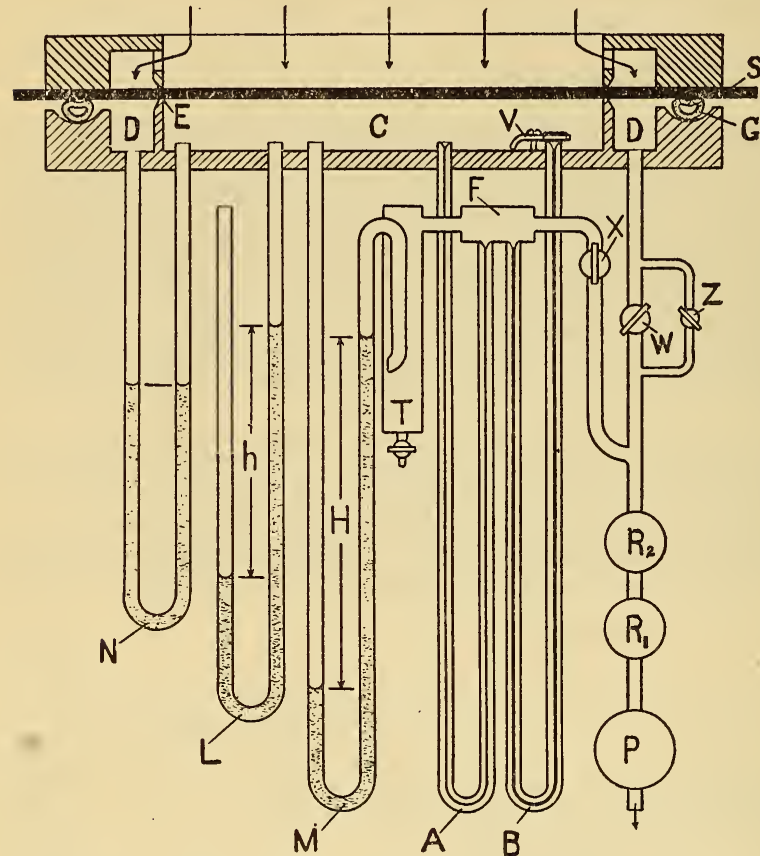

FIgURE 1.-Schematic drawing of the air permeability instrument used in the investigation. test. Air is simultaneously drawn from cells $\mathrm{C}$ and DD, the relative flow being controlled by valves $\mathrm{W}$ and $\mathrm{Z}$ until the two menisci in manometer $\mathrm{N}$ remain at the same level. With no lateral pressure gradient across the cell boundary $\mathrm{E}$, edge leakage into $\mathrm{C}$ is prevented. The volume of air flowing per second under a pressure difference $h$ through that part of $\mathrm{S}$ above cell $\mathrm{C}$ is known from $h$ and the calibration data of the capillary flow meter. The precision of the instrument is such that results are reproducible within one half of 1 percent.

A sensitive instrument of this character makes possible the investigation of a number of questions, about which there has been considerable uncertainty arising from differences of opinion of various investigators. One cannot find in the literature satisfactory answers to such questions as the relation of the rate of passage of air through paper to the pressure difference across the sheet; or the relation of this quantity to the area and thickness of the material, and to the temperature and relative humidity of the enveloping atmosphere. A knowledge of these relations is necessary to the very definition of air permeability, and without this knowledge it is impossible to set up adequate standards for air permeability measurements. These relations also give information about the structure of fibrous sheets and the probable nature of the air passages. 


\section{RELATION OF THE RATE OF FLOW OF AIR THROUGH} PAPER TO VARIOUS EXPERIMENTAL CONDITIONS

\section{THEORETICAL RELATIONS}

The air passages through paper are very small, having cross sections of capillary dimensions. The length of these passages is an unknown quantity; it may be anything from the thickness of the paper to a comparatively lengthy and devious course through the sheet. The cross-sectional contours are irregular in shape and variable in size. Although we do not have equations designed to describe completely the rate of passage of a gas through such a complex structure, we do have, on the one hand, an equation for a straight, tubular capillary the length of which is very great in comparison with the diameter, which is applicable when the flow is streamline; and on the other hand, an equation for the flow of a gas through a nozzle or orifice, which is applicable when the velocity of approach of the gas is small in comparison with the velocity within the orifice. Presumably, within these extremes should be found the essential conditions operative in the passage of air through a sheet of paper.

In the previous publication a simple equation was set down to evaluate the air flow through paper from the data obtained with the new instrument.

$$
V=d \cdot \frac{H}{h} \cdot \frac{\phi}{\rho H} \cdot \frac{B-d}{B}
$$

For convenience, this equation was also written in another form, applicable within the limits of ordinary laboratory conditions:

$$
\frac{V}{S d}=\frac{H}{h}(1-0.001 \rho h) C
$$

In these equations

$V=$ the volume of air, measured at the inlet (atmospheric) pressure $B$, which, at a given temperature, flows in unit time through the effective area $S$ of paper across which a pressure difference $d$ is maintained,

$\phi=$ the same volume, measured at the inlet pressure of the capillary,

$H=$ the pressure head across the calibrated capillary tube,

$h=$ the pressure head across the paper,

$\rho=$ the density of the manometer liquid, and

$C=\frac{\phi}{\rho \overline{H S}}$ a variable coefficient, corresponding to values of $H$, obtained from the calibration of the capillary tube and the known value of $S$.

Equation (1) depends simply upon Boyle's law, and applies, at the temperature of calibration of the capillaries, to any material whatever that can be tested with the instrument.

On the other hand, the equation which, according to Meyer, ${ }^{2}$ describes the flow of a gas through the ideal capillary tube may be expressed as follows:

$$
\phi P=\phi^{\prime} p=\frac{\pi r^{4}\left(P^{2}-p^{2}\right)}{16 \overline{l \eta}}=\frac{k}{\eta} \cdot D \cdot \frac{2 P-D}{2}
$$

${ }^{2}$ Annalen der Physik und Chemie, vol. 127, p. 253, 1866. 
in which

$\phi=$ volume of gas, measured at the inlet pressure $P$, which flows per unit time through the capillary tube,

$\phi^{\prime}=$ corresponding volume per unit time measured at the outlet pressure $p$,

$r=$ radius of the capillary tube,

$l=$ length of the capillary tube,

$\eta=$ coefficient of viscosity of the gas,

$k=\frac{\pi r^{4}}{8 l}$, a dimensional constant of the capillary tube, and

$D=P-p$, the pressure drop across the capillary tube.

From this equation we may write

$$
\frac{\phi}{D}=\frac{k}{\eta} \cdot \frac{2 P-D}{2 P}
$$

Presuming for the moment that the air passages through a sheet of paper behave as if they were a bundle of capillary tubes, we can, by analogy with equation 4 , write:

$$
\frac{V}{d}=\frac{K}{\eta} \cdot \frac{2 B-d}{2 B}=\frac{H}{h} \cdot C S \cdot \frac{B-d}{B}, \text { by equation } 1,
$$

in which $K$ is a structural constant of the paper, equivalent to $\Sigma k$ for all the capillary passages involved, and the other symbols have the same significance as in equation 1 .

If these air passages behave as capillary tubes, we can make the following deductions from the foregoing equations:

1. The constant $\frac{K}{\eta}$ of equation 5 is the limiting value of $\frac{V}{d}$ as $d$ approaches zero. When $d$ is small in comparison with $B$, the ratio $\frac{V}{d}$ should be nearly constant ( $V$ nearly proportional to $d$ ). It is logical that $d$ should be small in the measurement of air permeability, since most uses of paper in which air permeability is significant involve very small values for the pressure drop across the sheet. In the new instrument $d$ does not exceed about $10 \mathrm{~g} / \mathrm{cm}^{2}$. Hence if $d$ in the expression $\frac{2 B-d}{2 B}$ were neglected, the result would not be in error by more than 0.5 percent. The equation then becomes equivalent to that of Poiseuille.

2. In the type of measuring instrument used the air flow is affected by the viscosity of the air (a function of the temperature) in the same manner in both the capillary flow meter and the paper, if both are capillary in nature. Now, if equations 4 and 5 represent the behavior of the two elements of the instrument, the division of one by the other gives $\frac{D}{d}\left(=\frac{H}{h}\right)$ independent of $\eta$. Hence, for a given pressure difference the value of $\frac{V}{d}$ (corresponding to the temperature of calibration of the capillary) obtained from equation 1 should be independent of the actual temperature at which the paper is tested by means of this double-flow-meter principle. 
3. Since, according to equation 3 , the rate of flow of air is inversely proportional to the length of a given capillary, $\frac{V}{d}$ should be inversely proportional to the thickness of the sheet if the structure is homogeneous with respect to the thickness dimension.

4. Within experimental error the value of $V$, for a given value of $d$, should be independent of the absolute pressure $B$ over the ordinary range of barometric pressures. The calibrations of the capillaries should likewise be independent of the absolute pressure. This relation becomes evident when we substitute different values for $P$ and $B$ in equations 4 and 5 while keeping the pressure difference constant. For a pressure difference not exeeeding $25 \mathrm{~g} / \mathrm{cm}^{2}$, the absolute pressure may differ as much as 10 percent from the standard barometric pressure without altering the rate of air flow by more than about 0.1 percent for a given pressure difference. Although these equations indicate that the volume rate of discharge of air (expressed in terms of the pressure at, say, the inlet end) through a capillary at a given pressure difference is the same for all usual values of absolute pressure, it is curious that some investigators have attempted to correct the indicated volume rate of discharge to what it would be under standard conditions, by a mistaken application of Boyle's law.

If, on the other hand, we consider paper as in effect a sheet perforated by a myriad of small orifices we should expect, according to Buckingham, ${ }^{3}$ the following equation to more nearly describe the behavior of air passing through it:

$$
\frac{V}{d}=M \sqrt{T} \frac{\sqrt{\left(\frac{B-d}{B}\right)^{\frac{10}{7}}-\left(\frac{B-d}{B}\right)^{\frac{12}{7}}}}{d}
$$

in which $M$ is a constant involving the cross sectional areas of the orifices (but not their lengths), $T$ is the absolute temperature, and the other symbols have the same significance as in equation 5. From equation 6 we can then make the following deductions for a sheet periforated by orifices:

1. The ratio $\frac{V}{d}$ should not be constant with changing pressure difference, but should decrease rapidly as $d$ increases. For small values of $d$ it is nearly inversely proportional to the square root of $d$ by equation 6 .

2. We find, by dividing equation 6 by equation 4 , that $\frac{D}{d}\left(=\frac{H}{h}\right)$ is nearly proportional to the five fourths power of the absolute temperature, for ordinary room temperatures. ${ }^{4}$ Hence the value of $\frac{V}{d}$, determined with the new instrument and equation 1 , should differ from that corresponding to the temperature of calibration of the capillary by nearly one half percent for each degree $\mathrm{C}$ by which the testing temperature differs from the temperature of calibration.

3 B.S.Technologic Papers, vol. 14, (no. 183), 1920.

- The approximate equation $\eta=\eta_{o}\left(\frac{T}{273}\right)^{3 / 4}$ was used to express $\eta$ in terms of $T$ in equation (4). 
3. Since $M$ does not depend upon the length of the nozzles or orifices, the value of $\frac{V}{d}$ should be independent of the thickness of the sheet.

4. For a constant pressure difference the rate of passage of air through such a sheet should increase with decreasing absolute pressure. For example, the value of $\frac{V}{d}$ at standard barometric pressure is increased by about 5 percent, according to equation 6 , when the barometric pressure is reduced 10 percent.

The duration of the test and the area of the specimen are also implicitly involved in equations 5 and 6 , but a given change in either one of these quantities should affect the results in a like manner, whether the air passages behave as capillaries or as orifices, provided the material is homogeneous with respect to area and is not altered in structure by the testing conditions. Although the effects of varying these quantities in air permeability tests are not useful as criteria of the nature of the air passages, these variables will be treated along with the other experimental conditions because of their importance in the development of standards for air permeability measurements and because investigators do not agree as to their effects on the measurements.

The foregoing criteria for the nature of the structure of paper may be summarized as follows:

If the air passages behave as capillary tubes, $\frac{V}{d}$ should be constant with change in pressure difference, constant with change in temperature, inversely proportional to thickness, constant with change in absolute pressure.

If the air passages behave as orifices or nozzles, $\frac{V}{d}$ should be inversely proportional to the square root of the pressure difference, increase with increasing temperature, constant with change in thickness, increase with decreasing absolute pressure.

In the application of these criteria to the experimental data it should be emphasized that the values of $\frac{V}{d}$ reported do not depend in any way upon air-flow theory nor upon any assumptions about the nature of the air passages through the material tested, since equation 1 is based simply upon the calibration of the instrument.

\section{EFFECT OF PRESSURE DIFFERENCE ON RATE OF FLOW OF AIR}

The relation of the pressure difference across the sheet to the rate of flow of air through it is so important to the convenient measurement of air permeability and the expression of the results, and to the translation of the laboratory tests into practical significance, that considerable attention has already been given to the study of this relation. The various reports, however, record a considerable diversity of conclusions. Bergmann and Ludewig, ${ }^{5}$ working with leather, reported air flow proportional to the pressure difference, but Edwards, ${ }^{6}$ working with the same material, concluded that air flow is not truly proportional

s Jour. Int. Soc. Leather Trade Chem., vol. 13, p. 279, 1929.

'Jour. Int. Soc. Leather Trade Chem., vol. 14, p. 392, 1930. 
to the pressure difference. Schiefer and Best, ${ }^{7}$ working with textile fabrics at very low pressure differences, found the two quantities proportional for some fabrics, but not proportional for others. Several investigators have reported results for paper. Lhomme et Argy and Bard ${ }^{8}$ reported the air flow proportional to the pressure difference except for condenser paper. Potts $^{9}$ concluded that air flow is virtually proportional to the pressure difference, but pointed out that there are exceptions. Silvio ${ }^{10}$ at first reported the two quantities proportional, except for thin papers or papers of poor formation, and later concluded that air flow is proportional to the 0.925 power of the pressure difference. Stoewer ${ }^{11}$ found the two quantities proportional, but an anonymous investigator, ${ }^{12}$ replying to Stoewer, reported not even a semblance of proportionality between pressure difference and the rate of passage of air through paper.

A great many tests have been made with the precision air permeability tester to show, for various kinds of papers and fiber boards, the relation between the pressure difference and the volume of air transmitted per unit time. The value for $\frac{V}{d} \times 100$ are recorded in table 1 for values of the pressure difference between 0 and $12 \mathrm{~g} / \mathrm{cm}^{2}$.

TABLE 1.-Data showing the relation of air transmission to the pressure difference across the sheet

\begin{tabular}{|c|c|c|c|c|c|c|c|}
\hline \multirow{2}{*}{ Kind of material } & \multirow{2}{*}{$\begin{array}{c}\text { Thick- } \\
\text { ness }\end{array}$} & \multicolumn{5}{|c|}{$\begin{array}{c}\text { Ratio of air transmission to pressure difference for } \\
\text { pressure differences of }\end{array}$} & \multirow{2}{*}{$\begin{array}{l}\text { Differ- } \\
\text { ence, } \\
\text { first } \\
\text { and last } \\
\text { columns }\end{array}$} \\
\hline & & $\begin{array}{l}0 \text { to } 4 \\
\mathrm{~g} / \mathrm{cm}^{2}\end{array}$ & $\begin{array}{l}4 \text { to } 6 \\
\mathrm{~g} / \mathrm{cm}^{2}\end{array}$ & $\begin{array}{l}6 \text { to } 8 \\
\mathrm{~g} / \mathrm{cm}^{2}\end{array}$ & $\begin{array}{l}8 \text { to } 10 \\
\mathrm{~g} / \mathrm{cm}^{2}\end{array}$ & $\begin{array}{l}10 \text { to } 12 \\
\mathrm{~g} / \mathrm{cm}^{2}\end{array}$ & \\
\hline $\begin{array}{l}\text { Binders board } \\
\text { Lined board } \\
\text { Strawboard } \\
\text { Tag board } \\
\text { Parchment deed } \\
\text { Machine-finished book } \\
\text { Wrapping (no. } 2 \text { Kraft) } \\
\text { Bond- } \\
\text { Coated book } \\
\text { Machine-finished book } \\
\text { Newsprint } \\
\text { Supercalendered book } \\
\text { Mappaper } \\
\text { Manifold tissuee } \\
\text { Stereotype tissue } \\
\text { Glassine }\end{array}$ & $\begin{array}{l}m m \\
2.30 \\
1.10 \\
.95 \\
.40 \\
.165 \\
.140 \\
.125 \\
.115 \\
.090 \\
.090 \\
.080 \\
.075 \\
.065 \\
.065 \\
.040 \\
.040\end{array}$ & $\begin{array}{c}100 \mathrm{~V} / \mathrm{d} \\
1.434 \\
57.3 \\
198.9 \\
118.9 \\
2.097 \\
49.05 \\
269.3 \\
11.32 \\
6.82 \\
171.2 \\
517 \\
31.17 \\
10.65 \\
64.4 \\
27.42 \\
1.668\end{array}$ & $\begin{array}{c}100 \mathrm{~V} / \mathrm{d} \\
1.430 \\
57.2 \\
198.4 \\
118.6 \\
2.098 \\
48.74 \\
269.2 \\
11.35 \\
6.81 \\
171.2 \\
516 \\
31.30 \\
10.62 \\
53.2 \\
26.22 \\
1.558\end{array}$ & $\begin{array}{c}100 \mathrm{~V} / \mathrm{d} \\
1.430 \\
57.3 \\
198.8 \\
118.7 \\
2.103 \\
48.87 \\
269.1 \\
11.30 \\
6.81 \\
170.8 \\
515 \\
31.28 \\
10.62 \\
49.3 \\
25.79 \\
1.503\end{array}$ & $\begin{array}{c}100 \mathrm{~V} / \mathrm{d} \\
1.432 \\
57.5 \\
199.0 \\
118.3 \\
2.092 \\
48.85 \\
267.8 \\
11.32 \\
6.88 \\
171.2 \\
514 \\
31.07 \\
10.58 \\
44.5 \\
25.47 \\
1.466\end{array}$ & $\begin{array}{c}100 \mathrm{~V} / \mathrm{d} \\
1.429 \\
57.5 \\
197.9 \\
118.3 \\
2.084 \\
48.80 \\
267.4 \\
11.28 \\
6.82 \\
171.4 \\
511 \\
31.10 \\
10.56 \\
40.7 \\
24.88 \\
1.412\end{array}$ & $\begin{array}{r}\text { Percent } \\
0.4 \\
.4 \\
.5 \\
.5 \\
.6 \\
.5 \\
.7 \\
.4 \\
.0 \\
.1 \\
1.2 \\
.2 \\
.8 \\
36.8 \\
9.3 \\
15.4\end{array}$ \\
\hline
\end{tabular}

The values in each vertical column were determined at some pressure difference within the pressure range designated at the top of that column.

With the exception of a few of the thinnest papers, the rate of flow of air through the paper is proportional to the pressure difference to within a fraction of 1 percent. These data agree remarkably well with the relation predicted by equation 5 for a capillary-tube structure of paper. In all the tests that have been made the only exceptions

\footnotetext{
7 B. S. Jour. Research, vol. 6, (RP261), p. 51, 1931.

${ }^{8}$ La Papeterie, vol. 53, p. 1438, 1931; Pulp and Paper (Canada), vol. 33, p. 177, 1932.

' Proc. Tech. Sec. Papermakers' Assoc. Gr. Brit. and Ir., vol. 12, p. 91, 1931; World Paper Trade Rev., vol. 96 , p. 1257,1931 .

${ }_{10}$ Paper Makers' Mo. Jour., vol. 68, p. 433, 1930; and vol. 69, p. 194, 1931.

11 Wochbl. Papierfabr., vol. 64, p. 57, 1933.

12 Wochbl. Papierfabr., vol. 64, p. 174, 1933.
} 
found have been thin papers of rather poor formation, in most of which numerous "pinholes", or minute orifices, could be seen extending through the sheet. In these exceptional cases the relation of air flow to pressure difference tends in the direction predicted by the equation for an orifice. The criterion for orifice-like behavior, $\frac{V}{\sqrt{d}}=a$ constant, however, is not satisfied in any case met with, a fact which suggests, for these thin, poorly formed papers, a structure intermediate between capillary-like passages and orifices, or a structure made up of both.

\section{EFFECT OF TIME ON RATE OF FLOW OF AIR}

Stoewer ${ }^{13}$ has presented data to show that the air permeability of paper is a function of the time the paper is exposed in the air stream, and concludes that the pressure difference across the sheet produces a progressive change in the density of the fibrous structure. Although such an effect might result from excessive pressure differences, no evidence of such an effect has been observed within the range of pressure differences used in this investigation. It will be recalled that when the precision of the new instrument was being studied, it was found that successive tests made on a given specimen under carefully controlled conditions agreed within a few tenths of 1 percent. Further evidence is afforded by the data in table 1 . The several values for each material represent varying periods of exposure in the air stream, since all were obtained on the same specimen by successive adjustments of the pressure difference. The time period for each material was about the same as that in Stoewer's experiments.

Although the rate of passage of air through a given structure under given testing conditions is constant with time, the structure may change over a period of time. For example, many instances have been observed in which the air permeability of a specimen was altered after it had gone through a cycle of hygrometric changes, as will later be seen when the effect of humidity is discussed. Such an effect is evidently brought about by changes in the structural relations of the fibers as they absorb moisture and swell, or give up moisture and shrink. An unusual instance has been observed in which the air permeability of a specimen increased tenfold after it had been stored for a year subject to hygrometric changes indoors. Other specimens stored under the same conditions changed very little.

\section{EFFECT OF AREA ON RATE OF FLOW OF AIR}

Most investigators have assumed that the quantity of air flowing through paper in a given time is proportional to the area exposed in the permeability cell of the testing instrument. Hanson, ${ }^{14}$ however, has presented data indicating that the rate of flow is not proportional to the area exposed. His data show air transmission values in the ratio of 1 to 3.2 for areas in the ratio of 1 to 4 . He presumed a sufficient distortion of the structure, resulting from the clamping pressure at the boundary of the cell, to account for the discrepancy. The investigation of such a boundary effect, or other contributing factors inherent in the testing method, is complicated by the variability of paper and fiber boards. This difficulty has not arisen in the study of 
other variables because the tests can be made on an identical area of material.

It must be evident, upon reflection, that we do not know what the effective area is when there is a horizontal pressure gradient in the annular area between the clamping rings of the permeability cell. Some air must pass through the structure of the paper in this region, making the effective area greater than the nominal area bounded by the clamping rings. We are not justified, therefore, in concluding with Hanson that the quantity of air transmitted is not proportional to the area exposed to the air stream, because we do not know what this area is. Moreover, we are forced to the conclusion that in none of the twenty-odd designs of air permeability apparatus described in the literature is the test area known except approximately. Even when the sheet is clamped between rubber rings and sealed at the edges there must be some movement of air within the structure lying between the clamping rings.

It will be recalled that in the instrument shown in figure 1 the test area is bounded by a narrow ring of metal, and that the pressure drop through the sheet is precisely the same on both sides of this bounding ring. Hence the uncertainty in the test area is not greater than half the contact area of this ring with the material. If the ring is made very narrow and the test area large (since the ratio of periphery to area decreases as the area increases), the uncertainty in effective area can be made very small, but of course never zero. Is the effective area determined by the inside diameter of the bounding ring, by the mean diameter, or by some intermediate value? It is unlikely that it is represented by the inside diameter, since it has been observed that the quantity of air transmitted is decreased slightly by an increase in the clamping pressure. For example, the decrease in air transmitted was found to vary from a negligibly small amount for a thin, hard paper, to about three fourths of 1 percent for a thick, compressible material, when tests were made with a cell in which the contact area of the ring was about 1.5 percent of the test area, and the clamping pressure was varied from that just sufficient to make the balancing manometer function properly, to a pressure sufficient to indent the material.

In order that the effect of area might be studied, another permeability cell was made having an area approximately one tenth that of the original cell. A sheet was first tested in the large cell; then, within the area thus tested, seven tests were made with the small cell, the seven tests being symmetrically distributed so as to fairly sample the area tested in the large cell. Finally the whole area was again tested in the large cell. The average of the two tests with the large cell (which, for most of the materials tested, agreed to within about 0.3 percent) was then compared with the average of the seven made with the small cell. Although the materials for these tests were selected for uniformity rather than for variety, they represent considerable differences in characteristics which might be presumed to enter into the case. An antique book paper and a supercalendered book paper were selected for their widely different surface characteristics. The strawboard selected is thick and compressible in comparison with the bond paper, and its air permeability per unit thickness is more than a hundred times as great as that of the bond paper. When the results were calculated on the basis of the free area repre- 
sented by the inner diameter of the clamping rings there was a discrepancy of 3 percent or more, as shown by table 2 . When, however, they were calculated on the basis of the area represented by the mean diameter they were found to be in good agreement. The agreement is, on the whole, so good that we may conclude with confidence that the effective area is sufficiently well represented by the area enclosed within the median circle defined by the average diameter of the bounding ring, and that the quantity of air transmitted is proportional to this area for otherwise identical conditions.

TABLE 2.-Data showing the relation of the area of the sheet exposed in the air stream to the amount of air transmitted through it in a given time

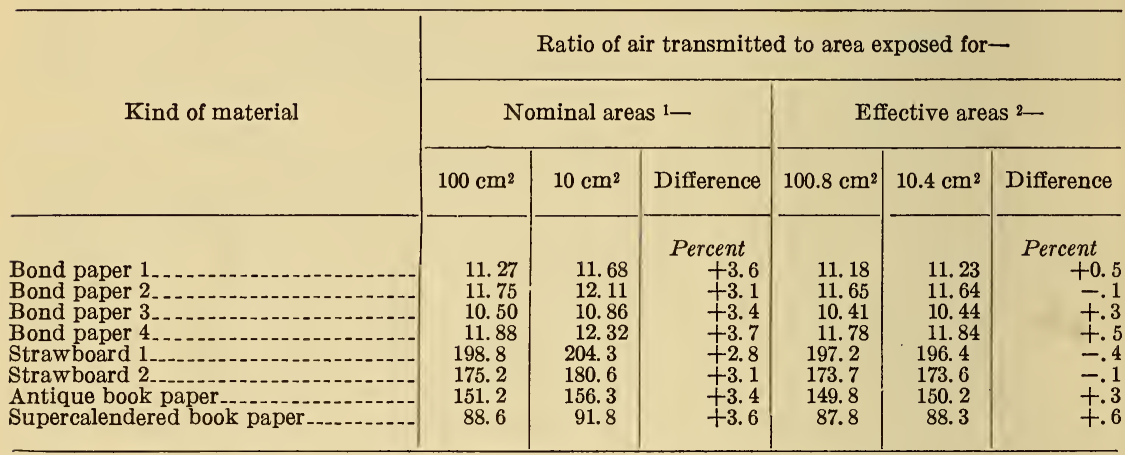

Area of cell aperture.

Area determined by the mean diameter of the bounding ring.

\section{EFFECT OF TEMPERATURE ON AIR PERMEABILITY}

Measurements were made of the flow of air through papers, fiber boards, and glass capillaries at a relative humidity of 65 percent and at temperatures of $27 \mathrm{C}$ and $21.5 \mathrm{C}$. According to conclusions reached in the section on theoretical relations, this difference in temperature should make no difference in the measurements if we are dealing with capillary phenomena in both the material tested and the capillary flow neter with which we measure the air flow. On the other hand, if the air passages in paper behave as orifices, we should expect the results at the higher temperature to be 2 or 3 percent higher than those at the lower temperature. The results of the measurements for 10 papers and fiber boards, in the order of decreasing air permeability, are shown in table 3. These data indicate that for ordinary room temperatures, the results by this method of measurement are practically independent of the temperature. This is not true for any of the displacement methods. Similar measurements for two capillary tubes at several values for the pressure difference are also shown in the table, being expressed as the ratio of air flow to pressure difference. These results do not, of course, imply that the actual amount of air going through the sheets or the capillary tubes at the two temperatures was not different, but that in each case the result obtained is the air permeability at the temperature of calibration of the flow meter. The agreement in results at different temperatures in table 3 is further evidence that the equation for flow through a capillary applies to paper and fiber boards, and hence that the air passages through them are capillary in nature. 
TABLE 3.-Air permeability measurements at different temperatures

\begin{tabular}{|c|c|c|c|}
\hline \multirow{3}{*}{ Kind of material } & \multicolumn{3}{|c|}{ Air permeability } \\
\hline & \multicolumn{2}{|c|}{ Tested at } & \multirow{2}{*}{ Difference } \\
\hline & $21.5 \mathrm{C}$ & $27 \mathrm{C}$ & \\
\hline $\begin{array}{l}\text { Mimeograph paper } \\
\text { Strawboard } \\
\text { Antique book paper } \\
\text { Lined strawboard } \\
\text { Supercalendered book paper } \\
\text { Sulphite manila tagboard } \\
\text { Rag index paper } \\
\text { Coated book paper } \\
\text { Sulphite index paper } \\
\text { Railroad board }\end{array}$ & $\begin{array}{c}\mathrm{cm} / \mathrm{sec} / \mathrm{m}^{2} / \mathrm{g} / \mathrm{cm}^{2} \\
282.8 \\
177.0 \\
151.1 \\
128.7 \\
86.9 \\
29.81 \\
11.28 \\
10.18 \\
8.69 \\
2.56\end{array}$ & $\begin{array}{c}\mathrm{cm} / \mathrm{sec} / \mathrm{m}^{2} / \mathrm{g} / \mathrm{cm}^{2} \\
281.3 \\
175.9 \\
151.0 \\
128.0 \\
86.9 \\
29.82 \\
11.29 \\
10.29 \\
8.68 \\
2.58\end{array}$ & $\begin{array}{r}\text { Percent } \\
-0.5 \\
-.6 \\
-.1 \\
-.5 \\
.0 \\
.0 \\
+.1 \\
+1.1 \\
-.1 \\
+.8\end{array}$ \\
\hline Capillaries & $100 \mathrm{~V} / \mathrm{d}$ & $100 \mathrm{~V} / \mathrm{d}$ & . \\
\hline $\begin{array}{l}\text { Capillary A }(d=24) \\
\text { Capillary A }(d=16) \\
\text { Capillary A }(d=11) \\
\text { Capillary B }(d=26) \\
\text { Capillary B }(d=18) \\
\text { Capillary B }(d=6)\end{array}$ & $\begin{array}{l}1.237 \\
1.241 \\
1.247 \\
8.98 \\
9.13 \\
9.38\end{array}$ & $\begin{array}{l}1.238 \\
1.241 \\
1.244 \\
8.95 \\
9.12 \\
9.36\end{array}$ & $\begin{array}{r}+.1 \\
.0 \\
-.2 \\
-.3 \\
-.1 \\
-.2\end{array}$ \\
\hline
\end{tabular}

A very important requisite in these tests was the protection of the materials from a change in equilibrium moisture content during the interim between tests at the two temperatures, for otherwise a slight change in structure might ensue. During the interim the materials were kept in an airtight package. Preliminary experiments in which this precaution was not taken were inconclusive.

\section{EFFECT OF RELATIVE HUMIDITY ON AIR PERMEABILITY}

The theoretical relations which we have considered do not give us any clue as to what effect the relative humidity of the air might be expected to have on the rate of flow through minute passages, except for the change in the viscosity of the air; and it has just been seen that a change in viscosity (a function of temperature) will not affect the results. There are certain characteristics of minute passages, however, which lead us to suspect the influence of relative humidity. Very small capillaries are prone to condense water vapor. Obstruction of this nature might be serious at high relative humidities. We should expect this difficulty, if any, with fine glass capillaries used as standards. Tests were made of the behavior of the two capillary tubes in the instrument having the smallest bores, at relative humidities of 65 percent and below. There was no evidence of fouling by condensation at these humidities.

In the case of paper, we should expect in addition a change in the structure of the sheet to result from the exposure to atmospheres of different relative humidity. The walls of the fibers take up moisture and swell as the relative humidity is increased. This swelling probably increases the size of passages within fibers, but may either increase or decrease the size of passages between fibers, depending upon conditions within the structure. Although we should expect a

49727-34-6 
change in relative humidity to affect the air permeability of paper, we are unable to predict either the magnitude or the direction of this effect. Gallagher, ${ }^{15}$ Hanson, ${ }^{16}$ and L'homme et Argy and Bard ${ }^{17}$ found little or no effect of changing relative humidity on the air permeability of paper. Herzberg ${ }^{18}$ concludes that the swelling of the fibers with increasing relative humidity results in decreasing the air permeability of paper. Stoewer ${ }^{19}$ presented data to show that papers made with little beating increase considerably in air permeability with increasing relative humidity, but that papers made of well-beaten stock decrease somewhat in air permeability with increasing relative humidity.

The same 10 materials appearing in table 3 were tested at a constant temperature and at relative humidities of 45,55 , and 65 percent, and finally again at 45 percent. An identical area of each sample was tested throughout to eliminate the effect of the inherent variability of the material, as has been done in all these studies whenever possible. During the interval between successive exposures and tests under different conditions the specimens were sealed in an airtight receptacle with relatively little free space, so that the moisture content of the specimens could not change appreciably. Under these carefully controlled, though limited range of conditions, appreciable effects of the humidity of the air on air permeability were found. But some materials increased while others decreased in air permeability for a given change in humidity. The largest change noted, however, was less than 4 percent. Two other sets of the same materials were tested over a wider humidity range, although the lower humidities were not under exact control, advantage simply being taken of low humidities in the laboratory on cold, dry winter days. One set was tested first at 10 and then at 65 percent relative humidity. The other set of samples was tested first at 25 , then at 65 , then at 10 , and finally again at 65 percent relative humidity. The results for the three sets of tests are summarized in table 4 as percentage changes in air permeability, for the relative humidity range and direction of change in humidity indicated at the top of each column. The materials are again arranged in descending order of air permeability, just as in table 3 .

These data indicate that the air permeability of some materials is very little affected by changes in relative humidity, while that of others may be altered at least as much as 15 percent within the range studied. If the higher range of humidities had been included in the study, considerably greater changes in air permeability might have been found. In general, the behavior of each material is characteristic, although there are some instances of rather erratic change both in direction and magnitude. Certainly, the structure is much less stable with changing relative humidity than with changing temperature when the humidity is constant. It is evident that comparable determinations of the air permeability of paper and boards must be made at a standard relative humidity, since we cannot tell beforehand how a given material will be affected by humidity changes.

15 Paper, vol. 33, no. 22, p. 5, March 1924.

16 See footnote 14 .

17 See footnote 8.

18 Papierprüfung, 6th edition, p. 216, 1927.

19 See footnote 11 . 
TABLE 4.-Daia showing the effect of relative humidity on air permeability

\begin{tabular}{l|r|r|r|r|r}
\hline & \multicolumn{2}{|c}{ Change in air permeability with change in relative humidity } \\
for-
\end{tabular}

\section{THICKNESS OF THE SHEET AND AIR PERMEABILITY}

For most uses of paper and fiber boards it is not necessary to bring thickness into the expression of the air permeability, since the overall value is the significant quantity. Sometimes, however, it is necessary to determine the porosity of the fibrous structure, as, for example, in paper-making studies involving the choice and treatment of raw materials and the formation of the sheet, and in studies of the relation of the structure of the material to its physical properties. In such studies the air permeability of a unit thickness of the material is of primary interest and presumes a knowledge of the relation between air permeability and thickness. This relation is also of considerable interest because of its bearing upon the nature of the air passages in paper.

From equations 5 and 6 we may infer that the quantity of air passing through paper should vary inversely as some power of the thickness of the sheet, the power being unity if the air passages behave as long capillary tubes, zero if they behave as orifices or nozzles, and somewhere between zero and unity if they have characteristics intermediate between orifices and long capillary tubes.

Emanueli 20 assumed air permeability inversely proportional to thickness and made use of the relation in evaluating his "porosity constant." A few investigators have reported data on this relation, but do not agree in their conclusions. Silvio ${ }^{21}$ made up sheets in various thicknesses from a given stock or fiber suspension, presuming the sheets to be alike except for the differences in thickness. After measuring the air permeability of these sheets he came to the somewhat startling conclusion that the volume of air transmitted per unit time, area and pressure difference is practically independent of the thickness except for very thin papers. In accordance with the theoretical criteria which we have discussed, this conclusion would indicate that the air passages behave as orifices for all except very thin papers, which is precisely the opposite of what we have found for all other criteria thus far considered. A somewhat similar finding is

${ }^{20}$ Paper Trade Jour., vol. 85 (TS98), 1927.

21 See footnote 10. 
reported by Seborg, Doughty, and Baird ${ }^{22}$ who likewise made up sheets in various thicknesses from a given fiber suspension. These investigators controlled also the solid fraction or apparent density of the sheets, so that their conclusions are all the more puzzling. They concluded that air transmission is nearly independent of thickness for a constant solid fraction, except when the solid fraction is less than 0.4 , that is, when the volume of the solid material (fibers) in the sheet is less than 0.4 of the volume of the sheet. For these more porous materials they concluded that air transmission increases with decreasing thickness. Potts ${ }^{23}$ used a different method and reached different conclusions. He tested thicker and thicker units built up by placing sheets of paper on top of one another. Using combinations of from 1 to 8 sheets, he came to the conclusion that air transmission is inversely proportional to some power of the thickness. This power was less than one for all the results he reported by this method, and was different for each kind of paper, being smaller for the denser papers. In conclusion, Potts says: "This is experimental proof that the interfiber spaces of paper are not simple capillaries, and that the thickness of the sample should not enter into the expression of permeability until we know more about its meaning." This investigator subsequently reported ${ }^{24}$ some tests of sheets made in various thicknesses from a given fiber suspension, according to the procedure of Silvio and of Seborg, Doughty, and Baird. These results correspond to a power greater than unity in Potts' equation, and are in strong contrast to the data of the other investigators who used the same method of attack, but who obtained data corresponding to the zero power of the thickness in the equation.

Both of the methods used by the investigators, whose studies have been summarized above, are somewhat at fault for the purpose of determining the effect of thickness upon air permeability. When sheets are made up in different thicknesses from a given stock there is no assurance that the structural pattern will remain constant. Especially if a hand-sheet machine is used, there is more than a possibility that the orientation of the fibers will change as the thickness of the fiber mat is increased. In fact Seborg, Doughty, and Baird suggest as much in their paper, although they assume an orifice-like mechanism in their perforated-plate analogy. It is conceivable that capillary-like passages of constant length in the different thicknesses of sheets might result from an orientation of the fibers such that they extend from surface to surface in all the sheets. It is difficult to explain otherwise the results obtained by Silvio and by Seborg, Doughty, and Baird. The writer has had an opportunity to test some book papers in different thicknesses, made at the Bureau of Standards on a semicommercial paper machine of the fourdrinier type. These papers were all taken from a single machine run, during which the density was maintained at a nearly constant value while the thickness was varied over nearly a threefold range. The results of these tests, which are shown in table 5, indicate, in contrast with the data reviewed above, that the air permeability is approximately inversely proportional to the thickness of the sheet, except for the very thin sheets. This method of approach may serve very well to explore the possibilities of making paper in different thicknesses so as

22 Paper Trade Jour., vol. 95 (TS144), 1932.

23 See footnote 9.

21 Proc. Tech. Sec., Papermakers' Assoc. Gr. Brit. and Ir., vol. 12, p. 118, 1931. 
to have certain characteristics of permeability, but it is inconclusive as a means of finding out how air permeability varies with thickness in a given material.

TABLE 5.-Data showing the relation of the air permeability to the thickness of sheets of paper made from a given fiber suspension, the density being nearly constant

\begin{tabular}{|c|c|c|c|}
\hline $\begin{array}{c}\text { Thick- } \\
\text { ness } \\
L\end{array}$ & $\begin{array}{c}\text { Air permeability } \\
A\end{array}$ & $A \times L$ & Density \\
\hline & & & \\
\hline$m m$ & $c m^{s} / \mathrm{sec} / \mathrm{m}^{2} / g / \mathrm{cm}^{2}$ & & \\
0.085 & 340.6 & 29 & $\mathrm{~g} / \mathrm{cm} s$ \\
.115 & 322.5 & 37 & 0.67 \\
.120 & 350.0 & 42 & .68 \\
.140 & 300.7 & 42 & .68 \\
.145 & 293.7 & 43 & .67 \\
.165 & 254.1 & 42 & .68 \\
.165 & 259.1 & 43 & .67 \\
.170 & 292.3 & 50 & .65 \\
.195 & 230.7 & 45 & .68 \\
.210 & 210.0 & 44 & .69 \\
\hline
\end{tabular}

The first method used by Potts, in which two or more sheets are tested together, is more suitable, although Potts overlooked some important points in the use of this method of approach. He assumed the air permeability of each sheet in the built-up unit to be the same, and erroneously considered it sufficient to multiply the air permeability figure of this built-up unit by the number of sheets in it, in testing the validity of the inverse proportionality between air permeability and thickness. It is necessary to: determine the air permeability of each sheet separately as well as to test them all in combination, and the identical area of each sheet must be exposed in the air stream when the sheets are tested separately and in combination. Although this investigator speaks of precautions to prevent leakage of air between the sheets, his results indicate that he did not prevent this type of leakage. In fact, it is a most difficult thing to do. Even with the instrument used in this investigation, which is designed to prevent a lateral pressure gradient at the cell boundary, it was found necessary, in order to prevent this type of leakage, to seal the edges of the sheets together for a little distance into the annular guard cell. Leakage of air between the sheets at the edges of the permeability cell would account for just the sort of results which Potts obtained: The air transmission decreased less rapidly than the increasing number of sheets would demand, and this tendency became more pronounced as the less permeable types of paper were tested. This type of edge leakage is a far more logical explanation of the type of results obtained than the paradoxical alternative of presuming that the air passages become more and more orifice-like as we deal with papers which are less and less permeable to air.

If two sheets are laid together and tested for air permeability, and if $V$ is the volume of air through a given area in unit time, $d$ the pressure difference across both sheets, $d_{1}$ and $d_{2}$ the pressure difference across the first and the second sheets, respectively,

$$
\frac{V}{d}=\frac{V}{d_{1}+d_{2}}=\frac{\frac{V}{d_{1}} \cdot \frac{V}{d_{2}}}{\frac{V}{d_{1}}+\frac{V}{d_{2}}}=\frac{a b}{a+b},
$$


in which we let $a=\frac{V}{d_{1}}$ and $b=\frac{V}{d_{2}}$. This relation would probably hold regardless of the nature of the air passages, because the sheets are in series with an air space between, in consequence of which the velocity of approach to each sheet is small in comparison with the velocity within the air passages. However, if the air passages behave as a group of capillary tubes, we can evaluate $\frac{V}{d_{1}}$ and $\frac{V}{d_{2}}$, notwithstanding the fact that we do not know the values of $d_{1}$ and $d_{2}$, because, in that case, each of these ratios is constant for all small values of the pressure difference. Hence we can evaluate these quantities by testing the two sheets separately at any convenient, small pressure difference. Equation 7 , therefore, is a criterion for the nature of the air passages when two sheets are tested, first separately and then in combination, and when the precautions aiscussed above are taken to prevent leakage between the sheets. Results obtained in this way are shown in table 6 . A more convincing variation on this procedure, which eliminates the air space between the sheets, is effected by wet-pressing the sheets together so as to make a loosely bound unit.

T $\triangle \mathrm{BLE}$ 6.-Relation of air permeability to thickness, shown by tesis of sheets made separately and in combination

\begin{tabular}{|c|c|c|c|c|}
\hline \multirow{3}{*}{ Kind of paper } & \multicolumn{4}{|c|}{ Air permeability of sheets tested- } \\
\hline & \multicolumn{2}{|c|}{ Separately } & \multicolumn{2}{|c|}{ In combination } \\
\hline & $\begin{array}{c}\text { First sheet } \\
a\end{array}$ & $\underset{b}{\text { Second sheet }}$ & $\begin{array}{l}\text { Calculated } \\
\frac{a b}{a+b}\end{array}$ & Experimental \\
\hline $\begin{array}{l}\text { Ledger paper } \\
\text { Bond paper } \\
\text { Rope manila paper } \\
\text { Strawboard. }\end{array}$ & $\begin{array}{c}\mathrm{cm}^{3} / \mathrm{sec} / \mathrm{m}^{2} / \mathrm{g} / \mathrm{cm}^{2} \\
5.175 \\
9.74 \\
107.5 \\
183.0\end{array}$ & $\begin{array}{c}\mathrm{cm}^{3} / \mathrm{scc} / \mathrm{m}^{2} / \mathrm{g} / \mathrm{cm}^{2} \\
5.310 \\
10.43 \\
109.2 \\
176.5\end{array}$ & $\begin{array}{c}\mathrm{cm}^{3} / \mathrm{sec} / \mathrm{m}^{2} / \mathrm{g} / \mathrm{cm}^{2} \\
2.618 \\
5.040 \\
54.20 \\
89.9\end{array}$ & $\begin{array}{c}\mathrm{cm}^{3} / \mathrm{sec} / \mathrm{m}^{2} / \mathrm{g} / \mathrm{cm} \mathrm{l}^{2} \\
2.619 \\
5.037 \\
54.15 \\
89.4\end{array}$ \\
\hline & \multicolumn{4}{|c|}{ Sheets wet-pressed together } \\
\hline $\begin{array}{l}\text { Writing paper. } \\
\text { Cover paper } . . . . .\end{array}$ & $\begin{array}{l}17.74 \\
202.1\end{array}$ & $\begin{array}{l}17.93 \\
175.3\end{array}$ & $\begin{array}{l}8.92 \\
93.9\end{array}$ & $\begin{array}{l}8.90 \\
93.6\end{array}$ \\
\hline
\end{tabular}

After it is dried and conditioned, this double sheet is tested without the edge seal, and then the two halves are peeled apart and tested separately. The last two papers in table 6 were treated in this manner.

These results clearly indicate that, if we increase the thickness of a sheet without altering any other structural characteristic, the new sheet behaves as if we have joined together capillary tubes, that is, as if we have increased the length of the capillary passages in proportion to the increase in thickness. From these experiments we may conclude that air permeability is inversely proportional to the thickness of the sheet, and that the air passages behave, according to the thickness criterion, as if they were long capillary tubes. 


\section{EFFECT OF ABSOLUTE PRESSURE ON AIR PERMEABILITY}

The effect of the absolute pressure on the air permeability of paper apparently has not figured in the studies of previous investigators reporting in the literature. According to equations 5 and 6, we should expect a change in absolute pressure (within usual limits) to have practically no effect on the air permeability of paper if the air passages behave as capillary tubes, but to have a significant effect if they behave as orifices.

Air flow measurements through capillary tubes and through paper were made with a calibrated capillary flow meter at various values of the absolute pressure between one atmosphere and about nine tenths atmosphere. The apparatus used is shown in figure 2. The reduction in absolute pressure on the inlet side of the test piece was obtained by attaching a small capillary tube $\mathrm{R}$ to the inlet of the test piece so

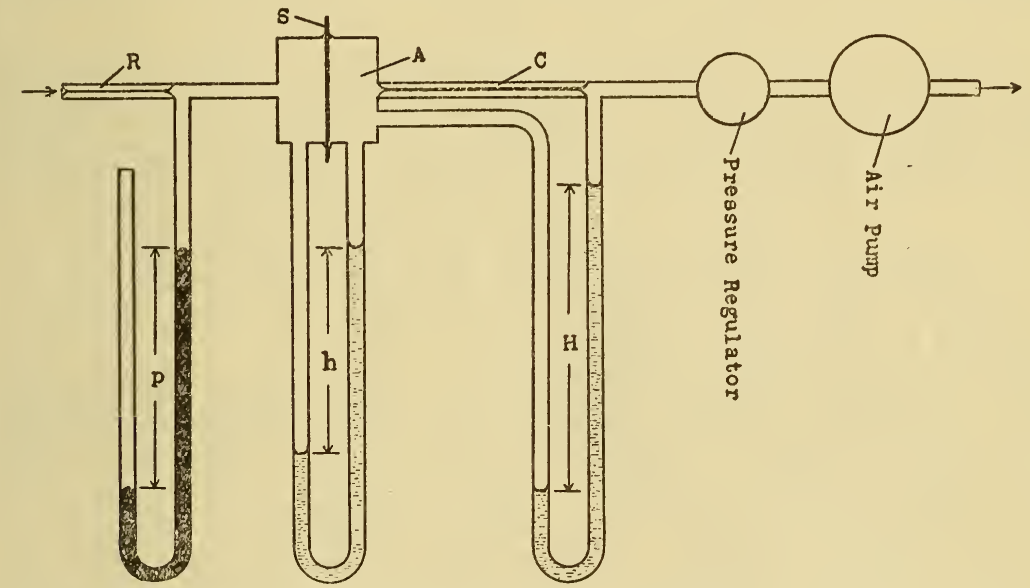

FIgURE 2.-Apparatus used in experiments at different absolute pressures

that the required pressure drop $p$ would take place through this capillary. A mercury manometer was used to measure this drop. The paper $\mathrm{S}$ was sealed with melted beeswax between the two halves of the permeability cell A so no air could leak in at the edges. For most of the tests this cell was made of two glass funnels butted together. Although the effective area of the specimen was not known, it was constant for a given specimen at the different absolute pressures. When measurements were made on the capillaries of the instrument shown in figure 1 , these capillaries were connected in place of the permeability cell $A$ of figure 2. The air flow was measured with the calibrated capillary C. Kerosene manometers were used to measure the pressure drop across this capillary and that across the specimen S. The apparatus was tested for leakage at the maximum value of $p$ which was to be used. The volume of air passing through the test piece was, as usual, expressed in terms of the inlet pressure on it. The air flow was first measured at atmospheric pressure with the capillary $\mathrm{R}$ disconnected, and then at pressures 2 to 11 percent lower than atmospheric, as shown at the head of each column in table 7 . 
TABLE 7.-Increase in air flow with decrease of absolute pressure

\begin{tabular}{|c|c|c|c|c|c|c|c|c|c|c|}
\hline \multirow{2}{*}{ Material tested } & \multicolumn{10}{|c|}{$\begin{array}{c}\text { Increase in air flow over that at a pressure of one atmosphere } \\
\text { at various decreases in absolute pressure }\end{array}$} \\
\hline & 2 & 3 & 4 & 5 & 6 & 7 & 8 & 9 & 10 & 11 \\
\hline Glass capillary 1 - & $\begin{array}{l}\text { Per- } \\
\text { cent }\end{array}$ & $\begin{array}{l}\text { Per- } \\
\text { cent }\end{array}$ & $\begin{array}{r}\text { Per- } \\
\text { cent } \\
0.4\end{array}$ & $\begin{array}{l}\text { Per- } \\
\text { cent }\end{array}$ & $\begin{array}{r}\text { Per- } \\
\text { cent } \\
0.2\end{array}$ & $\begin{array}{r}\text { Per- } \\
\text { cent } \\
0.6\end{array}$ & $\begin{array}{l}\text { Per- } \\
\text { cent }\end{array}$ & $\begin{array}{l}\text { Per- } \\
\text { cent }\end{array}$ & $\begin{array}{r}\text { Per- } \\
\text { cent } \\
0.7\end{array}$ & $\begin{array}{l}\text { Per- } \\
\text { cent }\end{array}$ \\
\hline $\begin{array}{l}\text { Glass capillary } 2 \\
\text { Glass capillary } 3 .\end{array}$ & & & - & 0.4 & & -1 & & & -.2 & $\begin{array}{r}0.2 \\
.5\end{array}$ \\
\hline Glass capillary 4 & & & -.3 & & & .0 & & & -.1 & \\
\hline Glass capillary 5 & & 0.2 & 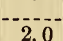 & & 2,1 & -.2 & & & .3 & \\
\hline Lined strawboard....... & 0.6 & & 1.2 & & 1.4 & $\cdots$ & 1.8 & & 2.9 & \\
\hline Ledger paper......... & .4 & 1.1 & & & 2.2 & $-\cdots$ & 2.8 & & & 4.0 \\
\hline Bond paper & 1.0 & -..... & 1.1 & 1.3 & 1.8 &..-- & 2.5 & & $-\ldots$ & 2.7 \\
\hline $\begin{array}{l}\text { Coated book paper } \\
\text { Double-coated book paper.- }\end{array}$ & & & & & 3. 6 & & & 5.3 & 7.5 & \\
\hline Alundum disc.... & & & & & & & & & .0 & \\
\hline
\end{tabular}

The data in table 7 indicate that the effect of change in absolute pressure on the flow of air through the glass capillaries is negligibly small, being both positive and negative and of about the magnitude of the experimental uncertainty. Number 1 of this group was the only one which appeared to show a consistent, slight increase. It is the one which might be expected to show the least effect, since it has the greatest ratio of length to diameter and, by the criterion of pressure difference, conforms very closely to rates of flow as predicted by the Meyer equation.

All the papers show an appreciable increase in air permeability with decreasing absolute pressure, and this increase approaches that predicted for an orifice-like structure. At first sight these data appear in sharp contrast with the nearly perfect agreement for a capillary-like structure of paper which we have found by all the other criteria applied. Some of the results in table 7, however, are too great to be explained on the assumption that the air passages do not behave as capillary tubes. Even if we should assume the air passages to be outright orifices, the greatest increase in air permeability which equation 6 would predict for the absolute pressure range in table 7 is about 5 percent. We note, however, that the last paper listed shows an increase of 7.5 percent. Moreover, this paper is well formed and of low permeability. When viewed under the microscope there is nothing to suggest air passages comparable in width to the thickness of the sheet. In fact, by the pressuredifference criterion, the air passages behave as long capillary tubes. Some other explanation must be found for the increase in air permeability of the papers in table 7 . The most likely explanation is a slight expansion of the structure of the sheet when the pressure on the surfaces is reduced, rather rapidly, in the experiments. The expansion in the structure must be elastic, because the air permeability at a given absolute pressure is nearly always a reproducible quantity. An extremely small expansion would be sufficient to account for the results, since the rate of flow of air through a capillary varies as the fourth power of the diameter. The reproducibility of the data for a given decrease in the absolute pressure suggests that the expansion of the structure may be associated with expansion in those voids which do not communicate with the exterior. 
If the hypothesis of expansion of the structure is correct we should expect a structure that is more rigid than paper to show a smaller effect for a given change in absolute pressure. An alundum disk about $2 \mathrm{~mm}$ thick and more porous than any paper in table 7 was tested in the apparatus of figure 2 , and the result is given as the last entry in table 7 . The effect of a 10 percent change in absolute pressure was barely perceptible.

Whether or not the apparent expansion of the structure indicated by these data would occur at higher altitudes is an open question. It may be a variable with differences in barometric pressure, or it may have been brought about by the comparatively rapid exhaustion of the air from the apparatus. From the practical standpoint, however, the influence of absolute pressure cannot be very significant in the testing of paper. In any given locality the fluctuation in barometric pressure is seldom greater than 1 or 2 percent of the mean annual value. Hence the uncertainty in air permeability measurement resulting from changes in absolute pressure would seldom be as much as 1 percent at a given place, even if we accept the data of table 7 as indicative of the effect of differences in barometric pressure. Great differences in altitude would, of course, bring the question into more prominence.

\section{NATURE OF THE AIR PASSAGES IN PAPER}

With the exception of the absolute pressure data, all the evidence which we have been able to focus on the question has indicated capillary phenomena within the structure of the sheet, and the apparent contradiction in the absolute-pressure data is easily explained on other grounds. The criteria of pressure difference, temperature, and thickness showed a remarkably close correspondence between experimental data (except for thin, poorly formed paper) and the theoretical equations for the flow of air through long, capillary tubes. This excellent agreement between experimental air-flow data and the theory of flow in capillary tubes is a noteworthy circumstance and throws considerable light on the structure of paper. It is certain that the thickness of the paper does not represent the length of the path through the paper, as has frequently been assumed. In order for the rate of flow of air through a capillary to be nearly proportional to the pressure drop, according to the Meyer equation, the length of the capillary must be very great in comparison with the diameter, of the order of a thousand times as great. Of the four glass capillary tubes in the instrument, only the smallest satisfied this criterion. The ratio of its length to its diameter is about 1,300 . The corresponding ratio of the next larger, which failed by some 2 or 3 percent of satisfying this criterion within the pressure range studied, was about 750 . Although we have little information about the behavior of meandering capillaries of irregular cross section, we cannot escape the conclusion that the length of the air passages through paper as compared with the width of these passages must be very great, in order for the air permeability data for paper to satisfy the theoretical equation for an ideal capillary. Knowing that there is great variation in size and shape of these air passages, and appreciating the tortuous course the air must pursue that the path may attain a sufficient 
length, we find it all the more remarkable that the data should agree so well with the theoretical equation for the simple case. The vegetable fibers of which paper is made are, of course, minute capillary tubes of fairly regular cross section. But during the preparation of the fibers the longer ones are cut into sections and considerable breaking down of the walls occurs. In the fabrication of the sheet the fibers become intricately entangled and pressure is applied to the sheet.

In the finished sheet, therefore, a round, straight, tubular passage would be so rare as to be inconsiderable. Some contend that the fiber canals play a minor role in the mechanism of transfer of a fluid through the sheet, the presumption being that the interstitial labyrinth provides chiefly the means of passage of the fluid. It is more probable, however, that both sets of passages are involved, since the wood fibers, which are so short as to require little cutting, contain many small orifices, or pits, through the walls, and the longer fibers, which do not contain the pits, are cut into sections open at both ends. An examination of cross sections of sheets of paper indicates that the fibers are usually much flattened and so closely compacted that the passages both within the fibers and between the fibers are ribbon-like, and that the widths (narrower dimension) of both kinds of passages are of about the same order of magnitude, which one estimates to range for the most part from about 1 to 10 microns. There are, of course, a considerable number of "caverns" of larger size, which presumably communicate with the labyrinthine pattern. In order for the length of the path of air through the sheet to be 1,000 or more times as great as the width of these passages, the path must be at least a few millimeters long (the order of magnitude of the length of the fibers in paper). But the thickness of some of the papers that behave according to the theoretical behavior of a capillary is considerably less than a tenth of a millimeter. The significant fact, which these data bring out, is that the lateral component of the length of the path of air in passing through a sheet of paper must be rather large in comparison with the normal component, which is the thickness of the paper. The tortuous course pursued may perhaps be something like 100 times the thickness of the sheet.

\section{SUGGESTIONS FOR A STANDARD METHOD OF MEAS- URING THE AIR PERMEABILITY OF PAPER}

\section{NOMENCLATURE, DEFINITION, AND UNIT OF EXPRESSION}

Several terms have been used rather loosely in the literature to describe the permeability of paper to air. In addition to air permeability, terms such as porosity, density, and air resistance have frequently been used almost interchangeably. Although air permeability is related to porosity and density, the test does not measure either. Air resistance, as sometimes used in paper testing, is reciprocally related to air permeability. This term is used in a very different sense in aerodynamics. Of the several designations, air permeability is the preferable term, since the primary definition of permeability relates to the ability of a material to permit the passage of a fluid through its porous structure. This is what is actually measured.

The definition of air permeability is difficult to set down in a single statement, since there are so many factors involved. In view of 
what has been learned in this investigation, perhaps the most logical and comprehensive definition is the following:

The air permeability of a fibrous sheet is measured by the limiting value, as the pressure difference approaches zero, of the ratio of the volume of air which passes in unit time through a unit area of the material to the pressure difference, the volume being measured at the pressure on the inlet surface of the material, and the air in contact with this surface being, throughout the test and for a sufficient time prior to the test for the establishment of hygrometric equilibrium, at a temperature of 21 degrees Centigrade, at a relative humidity of 65 percent, and at a pressure of one standard atmosphere. The limiting value of the ratio mentioned above is chosen because, according to equation 5 , it is proportional to a structural constant of the sheet.

For all except a few unimportant, thin papers, the ratio in the above definition is numerically equal to the volume of air that flows through the material per unit time, area, and pressure difference. Hence, for nearly all purposes, it is more convenient to define the air permeability of paper and fiber boards in the following manner:

The air permeability is measured by the volume of standard air which passes in unit time through a unit area of the material when urged by a unit pressure difference (not exceeding about $10 \mathrm{~g} / \mathrm{cm}^{2}$ ) between the surfaces of the sheet. Standard air, for the purposes of this test, is defined as air at $21 \mathrm{C}$, at 65 percent relative humidity, and at a pressure of one standard atmosphere.

It is unfortunate that we cannot omit the absolute pressure requirement from the definition of air permeability, as the theory of capillary flow would permit within the ordinary range of barometric pressures. It is very inconvenient to require a definite barometric pressure for the air in which air permeability tests are made, but, since the investigation has failed to show the air permeability independent of the absolute pressure, we must for the present include a standard barometric pressure in a precise definition. Fortunately, the fluctuations of barometric pressure in a given locality are small enough that they produce effects within the experimental error of the testing instrument, a circumstance which makes it possible to obtain relative air permeability values without cognizance of the absolute pressure. Since the effect of absolute pressure on air permeability seems to be different for different materials, we have no means of converting air permeability values from one absolute pressure to another. Further investigation of this relation is very desirable in the interest of simplifying air permeability measurements.

Units of expression of air permeability are almost as numerous as are the designs of apparatus for making the measurement. The time required to displace a given volume of air through the test specimen is perhaps the most popular mode of expression. Few investigators have attempted to express the results so as to be intelligible in the absence of specific information about the apparatus and experimental conditions. Metric units, English units, and absolute units have been used. To conform to the definition suggested above, the unit of expression must involve the volume of standard air which flows through a unit area of the material in unit time for a unit pressure difference. The unit which has been found convenient in this investigation expresses the volume in cubic centimeters, the time in seconds, the area of material in square meters, and the pressure difference in 
grams per square centimeter and is abbreviated to: $\mathrm{cm}^{3} / \mathrm{sec} / \mathrm{m}^{2} / \mathrm{g} / \mathrm{cm}^{2}$. Although comprehensive, such an expression is rather awkward. Possibly we can look forward to the adoption at some time of a comprehensive definition of the unit of air permeability to which a simple name can be given in the manner customary in the field of electrical units. $^{25}$

\section{APPARATUS AND TESTING CONDITIONS}

This investigation has provided an accurate method of measuring the air permeability of paper and fiber boards, and, therefore, a means of appraising other methods of making the measurement. It has not, however, included such an appraisal, without which we cannot say to what extent other apparatus might be suitable. As a result of the investigation we can state the essential characteristics of a reliable apparatus. Such an apparatus should be so designed that conditioned air is caused to flow through the specimen, and the apparatus should measure all the air that comes through the area designated as the test area and no air from any other source. This requirement means an effective prevention of leakage across the clamping surfaces and through the edges of the specimen. An easy means should be provided for testing the apparatus as a whole against leakage. The pressure difference obtainable across the sheet should not exceed about $10 \mathrm{~g} / \mathrm{cm}^{2}$, and should be constant while the test is being made.

For precise work the experimental uncertainty should be as small as possible and the testing conditions should conform to the requirements of the definition in the previous section. For most ordinary testing, however, it is probable that an uncertainty of 2 or 3 percent would be permissible in the calibration of the apparatus, in the constancy of the pressure difference, in the value of the pressure difference, in the readings of the instrument, and in the effective area of the specimen. The absolute-pressure effect will, in general, be within this range of experimental uncertainty for stations under 2,000 feet above sea level. The air passing through the paper should be at $21 \mathrm{C}$ and 65 percent relative humidity, the standard paper testing conditions. The material tested should be in hygrometric equilibrium with this air.

Washnington, March 19, 1934.

\footnotetext{
${ }^{25}$ The name "perm" has been suggested for the fundamental cgs unit for the permeability to gases of all porous sheet materials. The "perm" would be defined as the volume of gas in cubic centimeters which flows per second through 1 square centimeter of the material under a pressure difference of 1 dyne per square centimeter $\left(\mathrm{cm}^{3} / \mathrm{sec} / \mathrm{cm}^{2} /\right.$ dyne $\left./ \mathrm{cm}^{2}\right)$. Practical units of convenient magnitude would then be derived from this fundamental unit. This would form a logical basis for the correlation of the numerous units of perme ability to gases used by different investigators and in different fields. The author wishes to acknowledge his indebtedness to H. D. Hubbard of the staff of the Bureau of Standards for these suggestions.
} 